\title{
Use of Digital Camera to Assess Nitrogen Status of Winter Wheat in the Northern China Plain
}

\author{
Liangliang Jia,' Xinping Chen, ${ }^{1, *}$ Fusuo Zhang, \\ Andreas Buerkert; ${ }^{2}$ and Volker Römheld ${ }^{3}$ \\ 'Department of Plant Nutrition, China Agricultural University, \\ Beijing, P.R. China \\ ${ }^{2}$ Institute of Crop Science, University of Kassel, \\ Witzenhausen, Germany \\ ${ }^{3}$ Institute of Plant Nutrition, University of Hohenheim, \\ Stuttgart, Germany
}

\begin{abstract}
The most widely used methods to assess the nitrogen (N) status of winter wheat (Triticum aestivum L.) are the determination of plant total $\mathrm{N}$ by combustion, the testing of nitrate in the leaf tissue and the use of SPAD readings. However, due to their labor requirements or high costs these methods can hardly be applied to the huge wheat
\end{abstract}

*Correspondence: Xinping Chen, Department of Plant Nutrition, China Agricultural University, Beijing 100094, P.R. China; Fax: 0086-10-62891016; E-mail: chenxp@mail.cau.edu.cn. 
growing areas of the Northern China Plain. This study therefore examined an alternative method to measure the $\mathrm{N}$ status of wheat by using a digital camera to record the visible green light reflected from the plant canopy. The experiment was conducted near Beijing in a multi-factorial field trial with three levels of $\mathrm{N}$. The intensity of green light reflected from the wheat canopy was compared to the total $\mathrm{N}$ concentration, to the nitrate concentration of the basal stem, and to the SPAD readings of leaves. The results show significant inverse relationships between greenness intensity, canopy total $\mathrm{N}$, and SPAD readings at booting and flowering. At booting, sap nitrate $<2000 \mathrm{mg} \mathrm{L}^{-1}$ was inversely related to greenness intensity and to sap nitrate concentration in the basal stem. At sap nitrate $\sim 2000 \mathrm{mg} \mathrm{L}^{-1}$, the greenness intensity reached a plateau. At booting and flowering, significant inverse relationships between greenness intensity and shoot biomass were found. The results show the potential of the new method to assess the $\mathrm{N}$ status of winter wheat.

Key Words: Greenness intensity; Nondestructive measurements; Photography.

\section{INTRODUCTION}

Winter wheat (Triticum aestivum L.) is one of the most important crops in the Northern China Plain and is usually fertilized with large amounts of mineral nitrogen $(N)$ to achieve high grain yields: In recent years, increasing concern about the nitrate concentration of the groundwater stimulated research to improve $\mathbf{N}$ fertilizer management in this region. ${ }^{[1]}$ To this end several methods such as the testing of sap nitrate in the basal stem and of soil Nmin levels have been employed to better match $\mathrm{N}$ demand and $\mathrm{N}$ supply. ${ }^{[2,3]}$ Plant total $\mathrm{N}$ concentration has often been used to assess the $\mathrm{N}$ status of crops but is time consuming and does not reflect well excessive $N$ supply. As a nondestructive and rapid method, SPAD readings have been recommended to determine the $N$ status in winter wheat. ${ }^{[4,5]}$ The shortcomings of this method are that the SPAD chlorophyll meter only allows to measure a small part of a leaf and a large number of random observations are usually needed to obtain a representative average value. Also the measurements are subject to operator bias in the selection of leaves and for the monitoring of large areas, the collection of SPAD meter data is too time consuming.

Alternatively, the testing of sap nitrate in the basal stem has been found to allow a reliable assessment of the $\mathrm{N}$ status of wheat. This method has also been used to predict yield and grain quality of wheat in 
field trials but has not been widely accepted by farmers because of the complexity of the method which involves a cutting of the stem combined with the use of chemical reagents or strips. ${ }^{[6]}$ Therefore, a rapid and inexpensive method to monitor a crop's $\mathrm{N}$ status in the field would be of great value to make wheat production in the Northern China Plain more environmentally sound.

The canopy color of crops reflects their $\mathrm{N}$ status. In corn it has been shown repeatedly that $\mathbf{N}$ deficient plants reflect more light over the entire visible spectrum than $N$ sufficient ones ${ }^{[7,8]}$ It has been proven that differences in light reflectance are usually largest for wave bands between 550 and $600 \mathrm{~nm}$. Research on soybean indicated that the light reflectance from leaves of plants grown at three different $\mathrm{N}$ rates differed most near $550 \mathrm{~nm} .{ }^{[9]}$ On the other hand, the green light reflected from plants and detected by the human eye has a peak wavelength of $550 \mathrm{~nm}$. This greenness is generally recognized as an indication of the $\mathbf{N}$ status in many crops. ${ }^{[8]}$ It shows the potential to use the light reflectance in the visible spectrum, especially in the green band, to determine the $\mathbf{N}$ status of crops.

The development of low-cost color digital cameras that use charge coupled device (CCD) arrays to capture images allows measurement of the intensity of light reflected on a plant canopy. Adamsen et al ${ }^{[10]}$ used a color digital camera to measure the greenness of a wheat canopy at the plot level by calculating the ratio of green $(G)$ to red $(R)$. Dymond and Trotter ${ }^{[1 i]}$ used a CCD array to obtain color images of forest and pasture targets from aircraft. They were able to calibrate the camera system and used it to evaluate the bi-directional reflectance properties of different targets. Lukina et al. ${ }^{[12]}$ used digital images captured by a color digital camera to estimate the vegetation coverage and biomass of wheat.

The objective of this study was to determine the feasibility of using a color digital camera to detect the $\mathrm{N}$ status of winter wheat and to compare it to the total $\mathrm{N}$ concentration, to the nitrate concentration of the basal stem sap and to SPAD readings.

\section{MATERIALS AND METHODS}

The properties of the loamy soil ( 0 to $0.3 \mathrm{~m})$ at the experimental site of Dongbeiwang, near Beijing, in northwestern of the Northern China Plain were a bulk density of $1.33 \mathrm{~g} \mathrm{~cm}^{-3}, \mathrm{pH} 8.0,17.3 \mathrm{~g}$ organic carbon $\mathrm{kg}^{-1}, 52.5 \mathrm{~g} \mathrm{CaCO}_{3} \mathrm{~kg}^{-1}, 34.6 \mathrm{mg}$ Olsen- $\mathrm{P} \mathrm{kg}^{-1}$, and $125 \mathrm{mg}$ $\mathrm{NH}_{4} \mathrm{OAc}-\mathrm{K} \mathrm{kg}^{-1}$.

The field experiment comprised a winter wheat/summer maize double cropping system, which involves planting and harvesting of one 
wheat and one maize crop each year. In this experiment, the first crop was summer maize, which was sown in June 1999 and harvested in September. From October 1999 to September 2001, two winter wheat/ summer maize rotations followed. All results presented in this article were obtained in the 2000/2001 winter wheat growing season.

The $3 \times 2 \times 3$ factorial split-split block experiment with four replications contained (i) three methods of irrigation as main plots of $60 \times 30 \mathrm{~m}$ comprising sub-optimal irrigation as a control, conventional irrigation at $384 \mathrm{~mm}$ split into four applications, and optimized irrigation at $310 \mathrm{~mm}$ split into six applications; (ii) two straw levels as sub-plots of $60 \times 15 \mathrm{~m}$ consisting of plus and minus straw recycling to the soil; and (iii) three levels of $\mathrm{N}$ application as sub-sub-plots of $20 \times 15 \mathrm{~m}$ comprising an unfertilized control, conventional $\mathbf{N}$ fertilization, and optimized $\mathbf{N}$ fertilization. Conventional $\mathrm{N}$ application as typically practiced by farmers in the Northern China Plain consists of $150 \mathrm{kgNha}^{-1}$ as $\mathrm{NH}_{4} \mathrm{HCO}_{3}$ before sowing and an additional $150 \mathrm{~kg} \mathrm{Nha}^{-1}$ as urea at booting. The optimized $\mathrm{N}$ fertilization treatment took into consideration the mineral $\mathrm{N}$ (Nmin) target value (split for three growth stages) for the envisaged yield and the Nmin level in the soil profile before sowing, at regreening and at booting.

Before the sowing of winter wheat in $2000 / 2001,55 \mathrm{~kg} \mathrm{Pha}^{-1}$ were applied as triple superphosphate (TSP) to all plots. Winter wheat, variety Jingdong 8, was sown in mid October 2000 at an amount of $187 \mathrm{~kg} \mathrm{ha}^{-1}$ with a row spacing of $15 \mathrm{~cm}$ and harvested in mid June 2001. During the $2000 / 2001$ winter wheat growing season, eight contrasting treatment plots were selected for the measurements reported in this article (Table 1). Their Nmin levels $(0-0.9 \mathrm{~m}$ soil depth) before sowing and the $\mathrm{N}$ rate applied are shown in Table 2.

Soil Nmin and plant total $\mathrm{N}$ analyses were done before sowing, at regreening [156 days after sowing (DAS)], booting (184 DAS), flowering (203 DAS), and after harvest (242 DAS). Five soil cores were taken from each plot and pooled at $0-30,30-60$, and $60-90 \mathrm{~cm}$ depth intervals. Subsequently, these samples were sieved, extracted by $0.01 \mathrm{~mol} \mathrm{~L}^{-1} \mathrm{CaCl}_{2}$ solution and $\mathrm{NH}_{4}^{+}-\mathrm{N}$ and $\mathrm{NO}_{3}^{-}-\mathrm{N}$ were analyzed by Continues $\mathrm{Flow}$ Analysis (TRRACS 2000).

Plant SPAD readings were taken with a Minolta SPAD ${ }^{\circledR}-502$ chlorophyll meter ${ }^{[13]}$ on 19 April (booting stage) and on 7 May, 2001 (flowering stage). For this purpose 30 first fully expanded leaves were randomly selected and measured to obtain an average value of each plot. At the same time, the aboveground plant biomass was harvested in $1 \mathrm{~m}^{2}$ sampling areas per plot, dried to constant weight at $70^{\circ} \mathrm{C}$, and analyzed for total $\mathrm{N}$ using the Kjeldahl method. At booting, the nitrate 
Table 1. Treatments of the soil fertility experiment selected for the nitrogen monitoring study in winter wheat of the Northern China Plain.

\begin{tabular}{|c|c|c|c|}
\hline Treatment & Irrigation & Straw & $\mathrm{N}$ fertilization \\
\hline 1 & Optimized & Without straw & $\begin{array}{l}\text { Continuous } 4 \text { crop seasons, } \\
\text { no } \mathrm{N} \text { fertilizer }\end{array}$ \\
\hline 2 & Optimized & Without straw & $\begin{array}{l}\text { Continuous } 3 \text { crop seasons, } \\
\text { no } \mathrm{N} \text { fertilizer }\end{array}$ \\
\hline 3 & Optimized & Without straw & $\begin{array}{l}\text { Continuous } 2 \text { crop seasons, } \\
\text { no } \mathrm{N} \text { fertilizer }\end{array}$ \\
\hline 4 & Optimized & Without ștraw & Current season no $\mathrm{N}$ fertilizer \\
\hline 5 & Optimized & Without straw & Conventional $\mathrm{N}$ fertilization \\
\hline 6 & Optimized & Without straw & Optimized $\mathrm{N}$ fertilization \\
\hline 7 & Optimized & With straw & Optimized $\mathrm{N}$ fertilization \\
\hline 8 & Conventional & Without straw & Conventional $\mathrm{N}$ fertilization \\
\hline 9 & Conventional & Without straw & Optimized $\mathrm{N}$ fertilization \\
\hline
\end{tabular}

Table 2. Initial levels of mineral nitrogen (Nmin) and $\mathrm{N}$ application rate $\left(\mathrm{kg} \mathrm{ha}^{-1}\right)$ in the treatments selected for this study on winter wheat of the Northern China Plain.

\begin{tabular}{lccccc}
\hline Treatment & $\begin{array}{c}\text { Nmin before } \\
\text { sowing }\end{array}$ & $\begin{array}{c}\text { Basal } \\
\text { fertilization }\end{array}$ & $\begin{array}{c}\text { Topdressing } \\
\text { at regreening } \\
\text { stage }\end{array}$ & $\begin{array}{c}\text { Topdressing } \\
\text { at shooting } \\
\text { stage }\end{array}$ & $\begin{array}{c}\text { Total N } \\
\text { supply }\end{array}$ \\
\hline 1 & 52 & 0 & 0 & 0 & 52 \\
2 & 64 & 0 & 0 & 0 & 64 \\
3 & 96 & 0 & 0 & 0 & 96 \\
4 & 103 & 0 & 0 & 0 & 103 \\
5 & 473 & 150 & 0 & 150 & 773 \\
6 & 112 & 0 & 17 & 47 & 176 \\
7 & 112 & 0 & 15 & 49 & 176 \\
8 & 461 & 150 & 0 & 150 & 761 \\
9 & 116 & 0 & 17 & 66 & 199 \\
\hline
\end{tabular}

concentration of the plant sap was tested with a Reflect Meter (Merck Co., Darmstadt, Germany). At maturity, in each plot three separate subsamples (each of size $3 \mathrm{~m}^{2}$ ) were harvested to determine grain and straw yield.

The digital pictures of the winter wheat canopy were obtained with an Olympus 2100L Digital Camera on 19 April (booting) and 7 May 2001 
(flowering). To work at a comparable solar angle and light intensity, all images were taken between 12:00 and 13:00 on clear days at $1.2 \mathrm{~m}$ above the ground and at an angle of $60^{\circ}$. Image resolution was $1024 \times 768$ pixels of 8 bit for red, green, and blue. Subsequently, the images of size $2.39 \mathrm{MB}$ were transferred in TIFF format to a computer and processed with Adobe Photoshop ${ }^{8}$ to extract color information.

\section{RESULTS}

At booting significant inverse relationships were found between greenness intensity and canopy total $N$ (Fig. 1) and between greenness intensity and SPAD readings (Fig. 2). For the relationship between sap nitrate with the greenness intensity, the latter reached a plateau when the sap nitrate concentration was above $2000 \mathrm{mg} \mathrm{L}^{-1}$ (Fig. 3A). At a sap nitrate concentration $<2000 \mathrm{mg} \mathrm{L}^{-1}$, however, the greenness intensity of the wheat canopy's image decreased with increasing nitrate concentration (Fig. 3B).

Significant inverse relationships were also detected between greenness intensity and shoot biomass at booting and flowering (Fig. 4). Canopy biomass decreased with increasing greenness intensity. The larger the biomass of wheat, the less green light was reflected from the canopy. At flowering, most of the color intensity came from canopy light reflectance, whereas at booting a large proportion of the color intensity came from soil reflectance.
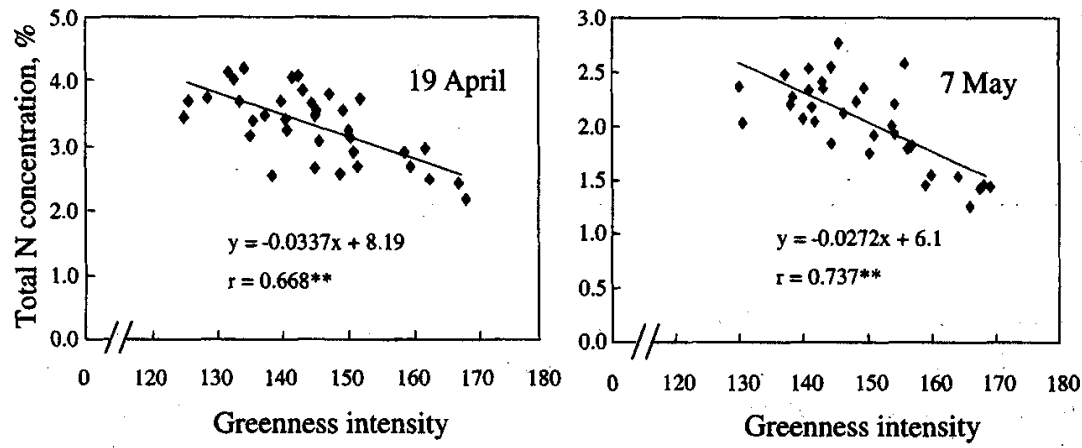

Figure 1. Correlation between total $\mathrm{N}$ concentration and greenness intensity of a wheat canopy at booting and flowering on 19 April and 7 May $2001(n=36)$. 


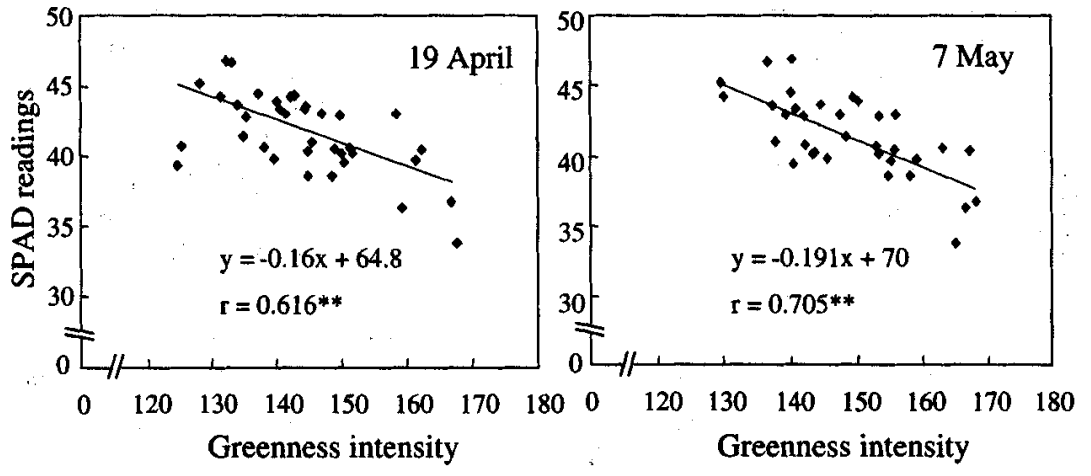

Figure 2. Correlation between SPAD readings and greenness intensity of a wheat canopy at shooting and flowering on 19 April and 7 May in $2001(n=36)$.

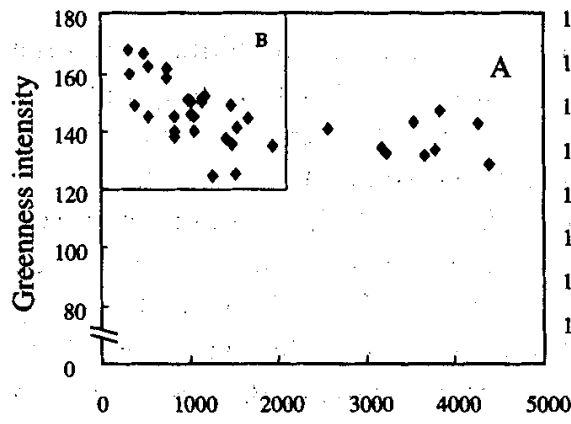

Sap nitrate concentration $\left(\mathrm{mg} \mathrm{L}^{-1}\right)$

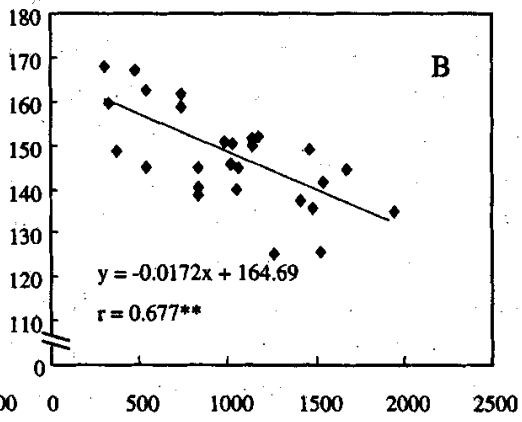

Sap nitrate concentration $\left(\mathrm{mg} \mathrm{L}^{-1}\right)$

Figure 3. Relationship between greenness intensity of a wheat canopy and the sap nitrate concentration in the basal stem at booting (Fig. B shows a detail of Fig. A at a nitrate concentrations below $2000 \mathrm{mg} \mathrm{L}^{-1} ; n=36$ for $\mathrm{A}$ and 27 for B).

\section{DISCUSSION}

The results of the digital image analysis technique correlated well with the other methods used to assess the $\mathrm{N}$ status of wheat. Significant correlations were found between the greenness intensity of the canopy image and plant total $\mathrm{N}$ concentration, sap nitrate, and canopy biomass. The correlation coefficients $(r)$ ranged from 0.6 to 0.8 . This shows the potential of using a color digital camera as a near-ground remote sensing 


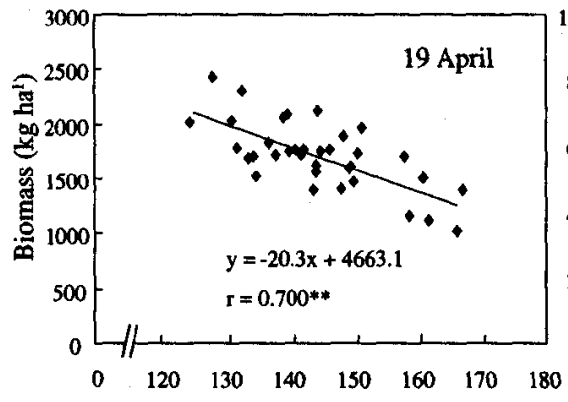

Greenness intensity

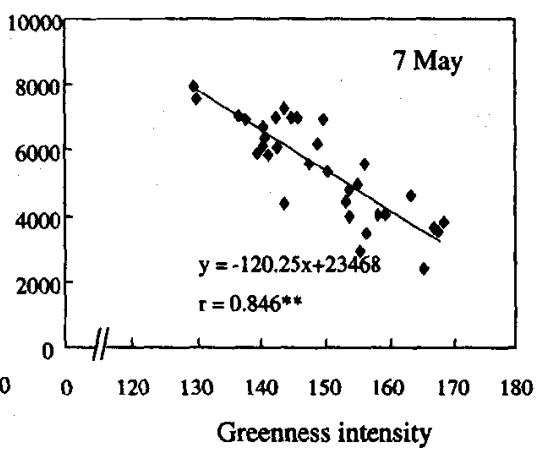

Figure 4. Correlation between canopy biomass and greenness intensity at booting and flowering of wheat on 19 April and 7 May $2001(n=36)$.

tool to detect the $\mathrm{N}$ status of wheat. Moreover, this technique shows the potential to estimate canopy biomass without destructive sampling. The results also suggest that the relative value of the $R, G$ and $B$ intensity or the $G / R, G /(R+G+B)$ ratio need to be considered for a more reliable assessment of the $\mathrm{N}$ status of wheat. Adamsen et al. ${ }^{[10]}$ used a green (G) to red $(R)$ ratio to measure the greenness of a wheat canopy and showed good correlations between $G / R$ ratios with SPAD readings. In the study presented here the correlations of the absolute $G$ value with the SPAD readings were higher than with the $G / R$ ratio or the $G /(G+R+B)$ ratio (data not shown). But in another experiment, the $G /(G+R+B)$ ratio was more reliable than the $G$ value (data not shown). This needs to be verified in further studies before more definitive conclusions can be drawn.

A canopy's greenness intensity as recorded by the digital image processing method is affected by many external factors. Soil reflectance, especially on light colored soils, the cloudiness of a particular day and the angle of view from which an image is taken are known as potential errors affecting the comparability of reflectance measurements over time and space. The limitation of such measurements to closed canopies can minimize the first source of error, whereas the control of light intensity and consistency in the angle of view depends on environmental conditions and the care of the operator. Nevertheless, even if these factors are controlled, simple field measurements of reflectance to monitor a crop's $\mathrm{N}$ status as presented in this study will only be successful as long as chlorophyll formation is dependent on $\mathbf{N}$ alone. With rapidly 
increasing resolution and data storage capabilities the use of digital images to assess a crop's $\mathrm{N}$ status will likely grow in the near future. Some recent camera systems even allow to directly record the nearinfrared (NIR) spectrum of reflected light, which is much less dependent on external errors and will therefore facilitate the monitoring of $\mathrm{N}$ in crop canopies at the field level by simple photometric methods.

\section{ACKNOWLEDGMENTS}

This research was financially supported by the Natural Science Foundation of Beijing, P.R. China (Project number 6002011) and the German Ministry for Education and Research (BMBF, project number 0339712A).

\section{REFERENCES}

1. Gao, W.; Huang, J.; Wu, D.; Li, X. Investigation on nitrate pollution in ground water at intensive agricultural region in Huanghe-huaihehaihe Plain. Eco-agric. Res. 1999, 7, 41-43, (in Chinese with English abstract).

2. Li, Z.; Zhang, F.; Wang, $X$. Nitrogen nutritional diagnosis and recommendation as topdressing fertilizer $\mathbf{N}$ for several crops in North China: diagnosis of nitrate in plant tissue by quick test method. Plant Nutr. Fert. Sci. 1997, 3, 269-274, (in Chinese with English abstract).

3. Chen, X.; Zhou, J.; Wang, X.; Zhang, F. Study on winter wheat $\mathrm{N}$ recommendation by soil Nmin test. Soil Fert. 1997, 21, 19-21, (in Chinese with English abstract).

4. Fox, R.H.; Piekielek, W.P.; Macneal, K.M. Using a chlorophyll meter to predict nitrogen fertilizer needs of winter wheat. Commun. Soil Sci. Plant Anal. 1994, 25, 171-181.

5. Blackmer, T.M.; Schepers, J.S. Use of a chlorophyll meter to monitor nitrogen status and schedule fertigation for corn. J. Proc. Agric. 1995, $8,56-60$.

6. Wollring, J.; Reusch, S.; Karlsson, C. Variable nitrogen application based on crop sensing. Proc. Fert. Soc. York, UK 1998, 423, 28-35.

7. Al-Abbas, A.H.; Barr, R.; Hall, J.D.; Crane, F.L.; Baumgardner, M.F. Spectra of normal and nutrient-deficient maize leaves. Agron. J. 1974, 66, 16-20. 
8. Blackmer, T.M.; Schepers, J.S.; Varvel, G.E. Light reflectance compared with other nitrogen stress measurements in corn leaves. Agron. J. 1994, 86, 934-938.

9. Chappelle, E.W.; Kim, M.S.; McMurtrey, J.E. Ratio analysis of reflectance spectra (RARS): an algorithm for the remote estimation of the concentrations of chlorophyll a, chlorophyll $b$, and carotenoids in soybean leaves. Remote Sens. Environ. 1992, 39, 239-247.

10. Adamsen, F.J.; Pinter, P.J.; Barnes, E.M.; LaMorte, R.L.; Wall, G.W.; Leavitt, S.W.; Kimbau, B.A. Measuring wheat senescence with a digital camera. Crop Sci. 1999, 39, 719-724.

11. Dymond, J.R.; Trotter, C.M. Directional reflectance of vegetation measured by a calibrated digital camera. Appl. Optics 1997, 18, $4314-4319$.

12. Lukina, E.; Stone, M,; Raun, W. Estimating vegetation coverage in wheat using digital images. J. Plant Nutr. 1999, 22, 341-350.

13. Piekielek, W.P.; Fox, R.H.; Toth, J.D., Macneal, K.E. Use of a chlorophyll meter at the early dent stage of corn to evaluate nitrogen sufficiency. Agron. J. 1995, 87, 403-408. 